

\title{
The Role of Simulation Exercises in the Assessment of Robustness and Resilience of Private or Public Organizations
}

Jean-Luc Wybo

\section{- To cite this version:}

Jean-Luc Wybo. The Role of Simulation Exercises in the Assessment of Robustness and Resilience of Private or Public Organizations. Hans J. Pasman and Igor A. Kirillov. Resilience of Cities to Terrorist and other Threats - Learning from 9/11 and further Research Issues, Springer-Verlag, pp.491-507, 2008, NATO Science for Peace and Security Series, volume 6, 978-1-4020-8488-1. 10.1007/978-1-4020-84898_23. hal-00569839

HAL Id: hal-00569839

https://hal-mines-paristech.archives-ouvertes.fr/hal-00569839

Submitted on 6 Sep 2012

HAL is a multi-disciplinary open access archive for the deposit and dissemination of scientific research documents, whether they are published or not. The documents may come from teaching and research institutions in France or abroad, or from public or private research centers.
L'archive ouverte pluridisciplinaire HAL, est destinée au dépôt et à la diffusion de documents scientifiques de niveau recherche, publiés ou non, émanant des établissements d'enseignement et de recherche français ou étrangers, des laboratoires publics ou privés. 


\title{
THE ROLE OF SIMULATION EXERCISES IN THE ASSESSMENT OF ROBUSTNESS AND RESILIENCE OF PRIVATE OR PUBLIC ORGANISATIONS
}

\author{
JEAN-LUC WYBO \\ Ecole des Mines de Paris, PO Box 207, 06904 Sophia- \\ Antipolis, France
}

\begin{abstract}
This paper deals with the organization of simulation exercises to prepare organizations to face emergencies. The original objective of such simulations is to train people to emergency procedures and devices; we raise the question of training people to face potential crisis situations: are simulations fitted to that objective? Through the observation of a number of exercises organized by private companies and rescue services, we can answer that naïve interpretation of simulation results limits their benefits to the correction of gaps between prescribed and observed actions, without addressing complex organizational behaviour. We introduce a method to organize simulations that gives access to this complexity and to the resilience and robustness capacities of the organization by giving specific roles to observers. This method uses a model of the organization seen as a combination of three levels: structures, relations and meaning.
\end{abstract}

Keywords: Emergency management, simulation of accidents, organizational learning, resilience, robustness

\section{Introduction}

With the growing complexity of technological and organizational systems, companies and public bodies have developed the use of simulations, exercises and drills in order to train their staff to face hazardous situations.

These simulations are related to emergency plans: dangerous situations or critical phenomena that have been identified as potential threats are 
played out and analyzed with the aim to define or check prevention and protection measures and to validate intervention plans. Exercise scenarios are designed to give people opportunities to "play the game" in realistic conditions, practice plans and test the use of technological devices.

Our observations and analysis of a series of simulations (toxic leak in a refinery, fire and toxic gas in road tunnels, terrorist attack in the metro, etc.) have shown the benefits but also the limitations of such simulations in terms of lessons (behaviors, decision making) learned by participants.

Among the benefits, the setting up of the exercise is in itself a good opportunity to gather the many stakeholders and to discuss "who is in charge of what"; this facilitates mutual knowledge among technical staff and shared values in the different organizations. The second kind of benefit is the test in realistic conditions of the technological devices and means (medical tents, fire extinction means, communications, etc.) and their use.

Among the limitations, the poor level of realism of the simulation is often an obstacle to the commitment of participants, who don't react as they would in a real, stressful situation. Another limitation lies in the evaluation method; people are evaluated for their strict application of plans, compared to "official" plans and procedures. Any difference in behavior is seen as a violation of rules and sanctioned or at least pointed to as an error, which strongly reduces people's willingness to innovate.

From this analysis, it can be concluded that simulations are efficient in creating opportunities for people to work together and to improve their practice of anticipated situations. But do simulations improve the ability of organizations to avoid or manage crises? Based on different non-participant observations and in-depth interviews, our answer is "no", to the extent that their analysis is limited to the identification and correction of deviations from the prescribed tasks.

We define a crisis as a situation in which an organization is overwhelmed and destabilized, as compared with emergency management, a situation in which the organization remains in control, applying known plans and procedures (Wybo 2004). In this context, resilience corresponds to the ability of the organization (at any level) to keep achieving its tasks by adapting its functioning to hazardous situations, uncertainty, time pressure and threats. Robustness corresponds to the ability of the organization to survive and stay under control by the emergence of new organizational patterns.

In observing simulations, we have identified individual and collective reactions to difficulties that were neither part of the scenario nor foreseen in the emergency plans. If the difficulties are relatively small, individuals and groups use their skills and experience to adapt plans, procedures and behaviors, in order to achieve their tasks in those degraded contexts. By 
doing so, they contribute to the organization's capacities of resilience. When faced with unanticipated and threatening events or situations, some people (generally the most experienced) show capacities of robustness: they emerge from the group, commit themselves to "do something" and find innovations to cope with the real situation. In some of those situations, new organizational patterns emerge, for example the creation of different communication flows or an alternate distribution of tasks. With such actions, those individuals and groups demonstrate their capacity to contribute to a higher level of robustness in the organization.

In order to go further in this reflection, we have designed a method to observe and analyze simulation exercises, allowing the identification of such behaviors, the context in which they appear and the lessons that can be learned from this analysis in terms of resilience and robustness capacities (Wybo, Jacques, Poumadère, 2006).

\section{The role of simulations}

\subsection{EMERGENCY MANAGEMENT AND RISK PERCEPTION}

It is now widely accepted that safety management inside the organization has to consider, in addition to the physical characteristics of dangers in the working place, the way risks are perceived by those involved.

The study of risk perception inside organizations deals with the comprehension of tasks and the definition of working situations when these may constitute a threat for the physical integrity of personnel, installations security, and even the safety and health of populations outside the organization.

Taking risk perception into account can be considered as one remedy for "normal accidents" as suggested by Weick (1986) who shows that systems vulnerable to normal accidents (Perrow, 1984) are at the same time contexts where individuals try to understand and manage complexity. Weick suggests preventive and learning actions through which individuals and groups become able to build elaborated interpretations of what they do and experience, leading them to analyze events other than those strictly limited to technical matters. Jacques \& al. (1999) have shown, using cognitive mapping, the evolution of learning over time by using preventive learning technique.

The challenge is thus for the organization to integrate safety management in two manners: first by taking into account human and organizational factors and not only technical factors of safety, and second, through involving fully all the actors inside the organization. When the risk 
of accident concerns outside populations, a wide array of stakeholders can be involved.

Safety integration can be achieved through training and preventive actions. A second way is through simulation. The specific advantage of simulation as a source of lessons is that it puts forward many aspects of what people prefer not to think about in their everyday working life situation: accidents and crises. In terms of perception, a simulated accident makes manifest events which otherwise might remain unknown, unseen and unheard of.

The simulation of a large accident involves many different players whose role is to intervene in case of accident. In normal times, these people do not meet nor are part of the high reliability organization (they are generally not part of the organization in charge of the routine activities). When the accident occurs, they must understand the situation, switch from the routine work to emergency management, cooperate and coordinate themselves in order to mitigate the accident and keep the situation under control. This very fact is in itself a complex organizational achievement, costly in terms of material and human resource mobilization.

Under normal operations, it is the occurrence of the accident that triggers a wide array of events, ranging from the focus of attention of personnel to the calling together of many outside players. The accident has the upper hand. In the case of simulation, the human minds of scenarists will take the lead. What difference does this make? This is what we aim to distinguish here, principally in terms of learning, which is chief among the assessment of resilience and robustness capacities of organizations.

Put simply, one can say that simulation creates for the organization an intermediate state between normal operations and crisis situations. While some of the preparedness required to face potential crisis situations can be acquired during normal times, other levels of learning can be acquired only outside normal situations, i.e. during crisis situations or simulations.

We focus in this paper on learning during simulation situations. To understand the dynamics of this type of learning, we have to consider some aspects of safety management in ordinary times. How safety is recovered during and after a crisis can then be examined on that basis.

\subsection{SAFETY MANAGEMENT IN NORMAL TIMES AND DURING CRISIS}

When a safety issue is raised, one may observe that everyone in the organization has an opinion on the question. While the starting point of this opinion is the shared objective to avoid accidents and prevent operational errors, reasoning and references, often implicit, may rapidly diverge. 
This can occur according to the position and role of the actor, his knowledge of risks and operations, possible defensive mechanisms that are in use in his working environment (Argeris \& Schön, 1996), (Dejours, 2000), orientations set by the hierarchy and the top management, etc.

In addition, the perceived contradiction between the a priori shared goal of a high level of safety and secondary divergences can lead to misunderstandings or stalled situations, which in turn are counterproductive for safety. The extent and efficiency of preventive actions, as well as communication with stakeholders, can thus suffer.

Organizations are bound by many levels of requirement or obligation in regard to safety assurance (Poumadère and Mugnai, 2006). The first level is individual obligation, which includes to follow consigns and basic rules, such as wearing the mandatory individual protections. Obedience is a must, along with the notion of self protection and, in some cases, that of survival. In most settings and most of the time, this level of obligation can appear disconnected from the apparent requirements of tasks. However, during accident and crisis situations, this basic level plays its full role and it is expected to be automatically integrated in behaviors. This context may restrain individuals to commit themselves to adapt procedures or innovate, as this behavior will be perceived as violations of rules.

Another level is that of economic obligation; simple economic rationality favors investments in prevention so as to avoid the very high direct and indirect costs of accidents. This level is most often disregarded during accident and crisis, as urgency prevails and exceptional expenditures may be undertaken. Even so, adaptations and innovations achieved on the spot are often done with very few resources, but without a clear evaluation of costs that may result later on from these actions (either in reduction or aggravation of damage).

The managerial obligation resides in the fact that safety figures among collective performance factors and must be managed to that effect, in itself and alongside other performance factors with which it is in interaction. During accidents or crisis, this managerial coordination of decisions is likely to be crucial, as long as the system remains under control of the organization. When the situation goes beyond the limits of routine, this obligation becomes less and less crucial compared to the willingness of players to do something useful at their own scale. In resilient organizations, the management will decentralize control and give to their staff more and more degrees of freedom in action as the situation escapes from control.

The legal obligation refers to the existence of the organization within a state of law, applied to all organizations which have to conform to established norms and prescriptions. Often this level prevails in the organization when safety is considered; i.e., safety actions and investments 
may be framed as responses to minimum legal requirements. However, during accident and crisis situations, the need to invent ad-hoc solutions and organizational patterns may make that level less predominant. In a similar way than individual obligation, legal obligation reduces the willingness for adaptation and innovation, as people may be sanctioned for violating rules, especially if there are casualties and financial damage.

The professional level of obligation corresponds to the best possible application of scientific and technical knowledge by Safety experts; in some contexts all members of the organization are invited to integrate safety within their professional identity. During degraded situations, experts tend to consider adaptations and innovations as a "normal way" to use their skills and experience when they have to cope with a risky situation. By doing so, they will be reluctant to talk about (either because they think that every professional would have done the same or because they want to keep secret what gives them the status of expert) and this "expertise in action" will not be shared and learned by other players.

The reciprocity obligation corresponds to interdependency and solidarity, which exist de facto within working relationships and make each of us responsible for others' safety, which can extend to relations with the environment of the organization and its protection. This obligation plays its role during degraded and crisis situations and contribute to organizational resilience as it governs interactions among players.

The moral obligation puts forward the value of human life, primordial within our cultural ethics, and for which better safety for all is a goal. This obligation plays an important role in the commitment of people when they perceive threats for other people.

These levels of obligation influence perceptions and role playing at all levels of the organization and thereby influence safety practices in routine activities and during emergencies. As shown above, obligations change in meaning and salience according to whether the organization is in a normal, degraded or crisis situation. It is thus useful in each context to assess safety obligation levels, both in ordinary times and for accident or crisis situations. The bridges built between these two different instants in organizational life can contribute to resilience and robustness if it is possible to observe and analyze them. This is our main objective during the simulation exercises.

\subsection{INTERPRETATIONS OF SIMULATIONS' ANALYSIS}

In the usual way of organizing exercises, one uses a rational model to measure the gaps between prescribed and observed actions as the scenario unfolds, and to explain in an objective way the causes of those deviations. This approach can be called "naïve", as it doesn't reach the complexity of 
the organization during emergencies and crisis. It can be associated with "simple-loop learning": measuring gaps and correcting them.

In this paper, we present a method to observe an organization during a simulation based on the plurality of specialized observers' points of view. Taking their observations together allows us to address the complexity of organizational behavior, to generate meaning and learning from the postsimulation analysis and thereby to go beyond the simple diagnosis of deviations from standard practice. The method is framed by a three dimensional model of organization: structures, relations and meaning:

"that of structures in which actors' games take place, that of relations between actors who set structures in motion, changing them through their games, giving rise to new organisational forms. This dimension also takes into account the principles of (sense making) legitimacy through which actors justify their games and their constructed orders." (Jacques and Specht, 2006)

\subsubsection{Structures}

Structures consist in what is prescribed by the organization, objectivable and measurable: the product of division of work, tasks, the means to achieve tasks, formal rules, procedures, technology, coordination tools and artifacts, etc.; what Minsberg (1993) calls the hierarchy line, technostructure and support services. This first layer allows the organization to deal with its routine tasks in a safe way: the "normal situation" is under control. It is associated with hierarchy: control is achieved by the management layer.

\subsubsection{Relations}

Relations are often represented as the roles played by the different actors. Following Crozier and Friedberg (1977), this dimension takes into account the fact that the structure is a context for action, which includes relations and interactions among people.

Each actor provides his resources, stakes, interests and power. This dimension can be observed at the micro/local level. It concerns verbal and non verbal, formal and non formal communication. It raises questions about the group's dynamics. This second layer gives the organization its flexibility to deal with deviations. By interacting, people adjust their activities to cope with changes from the routine conditions in order to proceed with their missions and put the system back into its normal state. This layer corresponds to the resilience of the organization. It is associated with networking: control is achieved by a series of adjustments and interactions at different levels of the hierarchy. 


\subsubsection{Sense}

Sense making is what people use to justify their actions; it is related to the notions of legitimacy, ethics, interests and values. The actor's representation of the situation influences his behavior. People belonging to different "worlds" have difficulties to act together for a common task (Boltansky and Thevenot, 1991), (Weick 1992).

Organizations that are able to make sense of ambiguous and uncertain situations demonstrate their plasticity to deal with unforeseen situations, pressure of events and uncertainty, and to avoid chaos and crises. This layer corresponds to the robustness of the organization. It is associated to emergence: control is achieved by people at any hierarchical level that invent ad-hoc solutions where and when they are needed to ensure the survival of the organization.

\section{Organization of simulation exercises}

In order to be prepared for emergency management activities, risk-prone companies and rescue services organize on a regular basis exercises that simulate accidents and catastrophes. In France for instance, a national regulation requests that all dangerous industrial sites organize once a year a large exercise with rescue services and local authorities.

The purpose of such exercises is to train people to apply procedures and plans, to become familiar with technical systems and locations, and to evaluate the efficiency and appropriateness of procedures. Their objective is also to give opportunities to the different organizations to communicate and act together. These practical sessions have one more advantage: they can be organized more frequently than staff turns over.

In this way, teams become accustomed to work together and if some need for improvement is identified, progress can be assessed during the next exercise, as it will be carried out by the same people in comparable conditions. This advantage is especially great when the exercise concerns very rare events and/or when the stakeholders have a high rate of turn-over. By running exercises at an appropriate frequency, the organization increases its capacities to face "known events".

\subsection{PREVENTION OF CRISIS: THE ROLE OF SIMULATIONS}

When dealing with the management of crisis situations, the interest of such exercises in terms of training can be questioned. Crises are situations in which plans and procedures are not appropriate, so how exercises can 
provide experience for such situations? How may exercises increase the resilience and robustness of organizations?

By placing observers in appropriate locations with precise missions during emergency exercises, we observed that people playing their roles in the exercise sometimes go beyond the procedures describing their tasks: when facing various types of difficulties (included or not in the scenario), they develop communication and coordination activities with other people (inside and outside their organization) and they adapt their activity to the real context in which they are. If the debriefing of the exercise is focused on the strict application of plans and procedures, such deviations and ad-hoc solutions are evaluated negatively by the management and so, they are generally hidden or minimized by the participants.

"Given the emphasis on plans, even those that are impossible to execute, it is not surprising that departing from them is often cited as evidence of a failure. Disasters, however, break the rules that guide the ordinary conduct of business and government, at least for a period of time. Disasters create new environments that must be explored, assessed, and comprehended, change the physical and social landscape, and therefore require a period of exploration, learning, and the development of new approaches", (Kendra and Wachtendorf, 2003).

These deviations from the standard procedures are indicators of the ability of people to adapt to difficulties and by that, they reveal on one hand the need for adaptation of procedures and on the other hand the resilience and robustness capacities of the organization: the ability of people and groups to be flexible and innovative to avoid destabilization and crises.

\subsection{ANALYSIS OF EXERCISES}

Simulating accident situations and collecting lessons learned is a challenge both for authorities and for other stakeholders involved. Accident is a sensitive situation including technical malfunctions, human errors and organizational flaws as root causes. Accident investigation in general is often closely focused on finding causes of the accident and less effort is put in studying organizational factors that influence the effectiveness of emergency management.

Beyond these difficulties, exercises provide an important source of information about emergency management in accident situations. The major advantage of simulated cases is that it is easier to collect lessons learned and to identify difficulties, if precautions are taken not to put too much pressure on participants about responsibility. Tackling the question of guilt can form an obstacle to the collection of relevant information about errors and organizational drawbacks from participants. 
Analysis of simulation exercises is based on a method which main objective is to develop organizational learning from accidents and crisis. This method was originally designed for the analysis of real accident situations in industrial plants, public transport (Wybo et al. 2002), floods and oil spills.

The method associates people who have been acting at different levels of hierarchy and in different organisms along the development of the situation. It is based on collecting individual stories from those who have been involved in the management of an accident situation and sharing these individual experiences among them in order to develop an organizational learning process.

In the case of real accidents, we select representative people that participated in the management of the accident at different levels of the hierarchy and from the different organizations (company, rescue services, officials, etc.).

In the case of simulation exercises, we introduce two categories of people in the process: a set of people that played the simulation and the group of observers. By this way, we get a chance to access the insights of the organization at work during the exercise and to identify aspects concerning the three levels: structure, interaction and sense.

Each interview starts with the interviewee telling his "own story". From that narration, the researcher points out the key moments in the story and asks questions like "why did you do that?", "how did you do that?", "what else could have been done?". By this way, relevant information about explicit knowledge (context, events, actions and decisions) can be identified from the story, along with some tacit knowledge: perceptions, motivations and alternatives. (Wybo 1998).

This knowledge is formalized as a set of "particles of experience". These particles of experience constitute the meaningful pieces of memories of each person having experienced a stressful situation. They represent either the person's reaction to an event or his actions to cope with a change in the current situation. An overall picture of the development of the situation is then drawn by the researchers, by merging information from individual stories into a collective story. Each particle of experience is divided into four phases:

- Context: the main aspects of the current situation;

- Analysis: how people perceived (on the spot) the situation and its evolution, and the hypothesis that were considered;

- Action: decisions made and actions carried out;

- Effect: a posteriori evaluation of effects of actions on the development of the situation. 
This common story is then discussed and validated during a "mirror meeting" gathering all participants, in order to reach an agreement among them and to identify lessons to learn from the management of that exercise.

The collective processing of individual perceptions, suggestions and experiences favors the commitment of participants to the conclusions reached during the process, which is very useful to promote learning in the organization and to apply the lessons learned in the future.

\subsection{OBSERVATION OF EXERCISES}

Based on this method, the introduction of specialized observers was tested in several exercises, in order to get the full picture of the organization at work and to identify these deviations from the prescribed world, from the combination of the points of view of the participants and the points of view of the different observers.

Three kinds of observers were defined: those who observe the activity of key people (information they receive and emit, people with whom they collaborate, decisions they make, etc.), those who observe a specific task (how it is achieved, difficulties encountered, who participates, what resources are used, etc.) and those who observe a specific place (who is there, what is done, how this place is perceived by people, etc.).

Using this combination of points of view (people playing roles and specialized observers), we build the "full picture" of the simulation that we present to the players during the debriefing session. This analysis results in the identification of a number of deviations, in particular the emergence of organizational patterns and communication flows among stakeholders, some of them proving efficient to prevent the situation from turning into crisis. Studying the character and value of these deviations makes it possible to capitalize on them to improve emergency procedures and plans, and to increase the mutual knowledge and efficient cooperation of stakeholders (Wybo, 2006).

"The reliability of learning of an organization is if it develops common understandings of its experience and makes its interpretation public, stable and shared." (March, Sproull, Tamuz, 1991)

\subsubsection{Case 1: assessment of resilience capacities}

We present here an example of this method to the simulation of an emergency in a road tunnel. The scenario was: a truck carrying a toxic gas tank stops in the tunnel as its tank is leaking; the driver goes to the nearest emergency shelter and calls the tunnel control room; four cars and a bus are in the tunnel at that time and stop at a walking distance from the truck. 
This exercise was set to test the management of such accident and to understand the behavior of passengers before the rescue services reach the site. More than 200 rescue people participated in the exercise, plus passengers of vehicles, tunnel operators, policemen and officials in the control room. 30 observers participated in the instrumentation of the exercise.

During the exercise, the tunnel management software partially failed (this was not in the scenario) and it was no more possible for the operator to answer calls from rescue shelters in the tunnel with the usual hardware (PC display, mouse and audio helmet). He remembered that there was a secondary rack that permitted to answer those calls, but this rack was difficult to access (in a dark part of the room, near the ground) and the indication of the calling shelter number was difficult to read (small digits, not illuminated). Anyway, the operator took with him a paper map of the tunnel with indication of shelter phone numbers \& locations and began to answer calls.

By the way, he succeeded to get essential information from the people calling, reassure them and give them simple indications to be safe while rescue forces were on their way. This is an example of the robustness capacities of this operator, which allowed him to keep people safe in the tunnel and to give precious indications to rescue services (how many people, in which locations: cars, bus and shelters).

\subsubsection{Case 2: assessment of a lack of robustness}

On the other side, it is also possible to observe and understand some drawbacks that would ruin the efficiency of emergency management in a real situation.

In the simulation of another accident in a road tunnel, two observers were placed in the control room of the tunnel: one observing the manager on duty and the other observing the activity in the control room. At the same time, other observers were inside and outside the tunnel (15 observers participated in this simulation). When the simulated accident occurred (collision of a car with a truck, putting fire to both vehicles), some of the car passengers, shocked but not wounded, were wandering on foot in the tunnel, looking for an escape route, and the rescue services took a long time to localize and shelter them. In real conditions, those people would probably die from smoke heat and toxicity.

By combining observers' data, we identified the organizational cause of this difficulty. The control room operator was facing a set of video screens in which it was possible to observe these people wandering in the tunnel. At the same time, in a corner of the room, an operator from the rescue team had established a radio terminal to communicate with their colleagues in the 
tunnel and they were listening to the conversations over the radio. Finally, the manager on duty was trying to assess the situation and prepared to answer the requests that he could receive from the chief of rescue forces (located at one of the exits of the tunnel) or other stakeholders.

But the operator had not been told to report to the manager what he saw on the videos (he was trained to answer questions, not to be proactive) and the operator managing the radio terminal was not trained to identify problems that his colleagues encountered in their actions from what he heard over the radio, so none of them communicated to each other or to the tunnel manager.

When the analysis of the different observations (in the control room, in the tunnel, at the rescue headquarters, etc.) was carried out, this drawback appeared as a lack of capacities of sense making in this group of people: none of them took an initiative to invent a form of cooperation that was not defined in the emergency plan.

From this analysis, it was possible for the tunnel managers and the rescue officers to share these results with their staff and to set up improved emergency procedures. This analysis also pointed out the importance of interactions among people from different organisms and proactive behaviors to build resilience and robustness capacities; otherwise even the best structure (cameras and video screens, wireless communications, procedures, etc.) is useless in such degraded situations.

\section{Conclusion}

Simulations are one of the most efficient tools that can be used to train people to emergency situations, especially for situations with a low frequency of occurrence and a high potential of damage.

Emergency services and risk-prone companies have gained significant experience in the setting up of exercises and this practice contributes to the capacity of their organizations to face "planned" emergencies (reinforcement of the structure layer).

In order to face situations that may turn into crisis, because of surprise, speed of development, uncertainty, lack of resources or difficulties in communications among stakeholders, organizations need to assess and develop their resilience and robustness capacities. In this paper we have shown that exercises can contribute to that on the condition that their analysis goes beyond naïve interpretations and gives access to the complexity of organizational behavior, specially the levels of interaction and sense making.

The method presented here provides means to reach this objective with only minor changes in the simulation set up. By defining specific missions 
for observers based on a model of organizational behavior, it is possible to identify more precisely the organization's resilience and robustness capacities and handicaps.

\section{References}

Argyris, C. and Schön, D.A., 1996, Organizational Learning II: Theory, Method and Practice, Addison-Wesley.

Boltansky L. and Thévenot L., 1991, De la justification ; les économies de la grandeur, NRF Essais, Gallimard, Paris

Crozier M. and Friedberg E., 1977, L'acteur et le système, Paris, Seuil,

Dejours C., 2000, Travail : usure mentale, Bayard Editions, Paris, 281 pages

Jacques J.M., Roux-Dufort Ch. and Gatot L., ,1999, From post crisis to preventive learning, Proceedings of the Academy of Management Annual Meeting, Chicago

Jacques J.M. and Specht M., 2006, Cognition towards crisis: the blind man held a handful of snow ... and concluded that white was cold, International Journal of Emergency Management, Vol. 3, No. 1, pp. 21 - 32

Kendra J.M. and Wachtendorf, T., 2003, Creativity in Emergency Response after the World Trade Center Attack. In Impacts of and Human Response to the September 11, 2001 Disasters: What Research Tells Us. Special Publication \#39. Natural Hazards Research and Applications Information Center, University of Colorado, Boulder.

March J.G., Sproull L S and Tamuz M., 1991, Learning from samples of one or fewer. Organisation Science, 2(1), pp. 7

Mintzberg H., 1993, Structure et dynamique des organisations, Les Éditions d'organisation.

Perrow C., 1984, Normal accidents, New-York: Basic.

Poumadère M. and Mugnai C., 2006, Perception des risques et gouvernance de la sécurité industrielle. In Psychologie du risque: Identifier, évaluer et prévenir les risques, R. Kouabenan ed., Paris: DeBoeck.

Weick K.E., 1986, Interpretive sources of high reliability: Remedies for normal accidents. Colloquium on Organizational Behavior, Harvard University, Cambridge, U.S.A.

Weick K.E., 1992, 'Sense making in organizations: small structures with large consequences', in Social Psychology in Organizations: Advances in Theory and Research, J.K. Murnighan, ed., Englewood Cliffs, NJ: Prentice-Hall.

Wybo J.L. 1998, Gestion des dangers et systèmes d'aide à la gestion, in Introduction aux cindyniques, ESKA Paris, pp.177-201

Wybo, J-L., Colardelle, C., Poulossier, M.O. and Cauchois, D., 2002, A methodology for sharing experiences in incident management, Int. J. Risk Assessment and Management, Vol. 3, Nos. 2-4, pp.246-254

Wybo J.L., 2004, Mastering risks of damage and risks of crisis : the role of organizational learning, International Journal of Emergency Management, Vol. 2, No1\&2, pp. 22-34

Wybo J.L., 2006, Improving resilience of organizations by increasing mutual knowledge of stakeholders, Proceedings of the $3^{\text {rd }}$ International ISCRAM Conference, B. Van de Walle and M. Turoff, eds., Newark, NJ (USA), May 2006

Wybo J.L., Jacques J.M., Poumadère M., 2006, Using simulation of accidents to assess resilience capacities of organizations, in Resilience Engineering, Presses de l'école des Mines de Paris, pp. 350-358 